\title{
The Role of Money in Saudi Arabia: A Dynamic Analysis
}

\author{
HAMAD S. AL-BAZAI \\ Associate Professor \\ Department of Economics \\ College of Administrative Sciences \\ King Saud University-Riyadh, Saudi Arabia
}

( Received 24.7.1418H, and Accepted 14.2.1419H )

\begin{abstract}
This paper examines the role of money in the economy of Saudi Arabia using a vector autoregressive approach (VAR). Unit root tests show that logs of money supply (LM1), non-oil GDP (LNOY), and price level (LP) are difference stationary and cointegrated. Variance decompositions and impulse response functions reveal that there exists a bi-directional causation between money supply and nominal non-oil GDP and a unidirectional causation runs from LM1 to LP and from LNOY to LP. These findings suggest that inflation in Saudi Arabia may happen as a result of bottlenecks in supply side and/or a growth in money supply more than the growth in income. These results also lend partial support to the monetarist theory of inflation. Based on these results, it can be said that Saudi Monetary Agency (SAMA) might be able to successfully maintain price stability at consumer's level by targeting narrow money stock. However, tight monetary policy could have a strong feedback on output. Therefore, simultaneous fiscal measures may help in achieving a longer-term sustainable economic growth.
\end{abstract}

\section{Introduction}

The relationship between money, prices and income is one of the major subjects of controversy in macroeconomics. This relationship was considered settled with evidence interpreted as showing that money fluctuations adversely affecting income and prices. However, there is a disagreement between Keynesians and monetarists as to whether the direction of causation runs from income to money, or from money to income. The Keynesians treat money as a passive variable in the demand for money function where monetary authorities respond to increased money demand in an adaptive manner. In particular, Keynesians argue that changes in aggregate demand are expected to cause changes in prices. 
On the other hand, the monetarists assign an active role for money supply where an increase (decrease) in the money supply would affect directly, but with a distributed lag, the national income. Therefore, the money supply plays a crucial role in the determination of income. However, they contend that this effect is confined to shortrun. In the long-run, money is neutral. Also, monetarists claim that inflation is a purely monetary phenomenon and that in the long run the rate of inflation equals the rate of monetary expansion in excess of the growth of capacity output. ${ }^{(1)}$ Sims (1972) suggested a practical way to test for relationship between money and income using Granger's concept of causality. Since then, several researchers have applied this technique to the analysis of money-income relationship (i.e. Lee and Li (1983), and Quddus et al.(1989), among others). These studies utilized bivariate causality tests to investigate money-income and money-prices linkages which raise the possibility of an omitted variable bias. This study tries of overcome this problem by using a vector autoregressive (VAR) model to analyze the relationship between money, income and prices in Saudi Arabia. This technique is free of the simultaneity problems that frequently characterize single equation reduced forms. It has the advantage that it does not require stringent a priori assumptions regarding exogeneity and endogeneity. Nelson and Schwert (1982) showed that causality tests based on VAR are more powerful than the single-equation approach. Sims (1982) recommended use of the VAR over the more general structural modelling framework because the former does not impose any priori restrictions on the dynamic relationships among the variables. Although, Cooley and LeRoy (1985) criticized some common uses of the VAR technique, they pointed out that the VAR is still valid for many uses such as "determining the existence of Granger-causal ordering, even in the absence of any theoretical reason to expect them" $(\text { p.306 })^{(2)}$.

This paper considers the usefulness of the VAR methodology for assessing the role of money in explaining fluctuations in output and prices in Saudi Arabia. It examines the ability of money innovations to explain output and prices changes. Basically, a causality test will be used in order to ascertain the role of money in Saudi Arabia. Although, Saudi Arabia, an oil-rich developing country, provides a good case study, it received little attention. ${ }^{3}{ }^{3}$ The only exception is Rosser and Sheehan (1995). However, Rosser and Sheehan paper was confined to examining whether or not Saudi monetary policy is independent from oil policy. The current paper tries to address a broader issue by investigating the role of monetary policy in the Saudi economy. It is usually argued that money supply is determined by government expenditure. Since the government owns the oil sector and public spending is independent from private activity, this

(1) Although monetarists admit that non-monetary influences can temporarily impact the price level, they argue that the price level would subsequently return to its original level unless it is affected by a permanent change in the rate of monetary expansion.

(2) Other authors such as Leamer (1985) and Fackler (1985) have voiced some concerns about the validity of the VAR. The major concern is: under what circumstances can we interpret VAR results as structural and hence draw conclusions about policy questions.

(3) It is usually argued that monetary policy is ineffective in an oil exporting country. Therefore, this paper tries to shed some light on this issue. 
means that government expenditure is exclusively financed by money creation. This translates to a causal relationship running from money to non-oil income.

The paper is organized as follows. Section 2 gives a brief review of the literature and outlines the empirical methodology. Section 3 presents the empirical findings. Finally, section 4 summarizes and concludes the paper.

\section{Theoretical and Methodological Aspects}

The quantity theory is considered the earliest theory of inflation. Based on the assumptions that velocity of money $(\mathrm{V})$ is determined by institutional developments in the monetary sector and that the real sector is fixed at predetermined level (Y), the quantity theory of money can be interpreted as determining the general price level $(\mathrm{P})$. More specifically, the price level is proportional to the money supply $\left.\left(\mathrm{M}^{\mathrm{s}}\right) .{ }^{4}\right)$ In the long-run inflation is a monetary phenomenon. However, in the short-run, it is argued that money change can result in an inflation effect and output effect. Friedman (1970) argued that there is a direct causal relationship between the money supply and the rate of inflation. He stated that "inflation is always and everywhere a monetary phenomenon and can be produced only by a more rapid increase in the quantity of money than in output." (P.24). As a result, an inflationary spell cannot continue without monetary expansion. In their influential work, Friedman and Schwartz (1963) concluded that "throughout the near-century examined in detail we have found that:

(i) changes in the behavior of the money stock have been closely associated with changes in economic activity, money income, and prices.

(ii) The interrelation between monetary and economic change has been highly stable.

(iii) Monetary changes have often had an independent origin; they have not been simply a reflection of changes in economic activity." ( P.676)

In a more recent study, Friedman and Schwartz (1982) restated those basic propositions. They found that changes in money result in equiproportionate changes in the price level. Also, changes in money and nominal income were found to parallel each other with causality runs from money to income. It is assumed that money supply is exogenous and can be controlled by the monetary authorities. This proposition has been the subject of a fierce debate with mixed results. For example, Turnovsky and Wohar (1984) failed to find any identifiable relationship between the money supply and prices over the period 1929-1978 for the United States. On the other hand, Benderly and Zwick (1985) and Jones and Uri (1987) found that money supply caused inflation for the USA. For less developed countries, Togan (1987), Fadil (1989), Jones and Sattar (1988) and Parikh (1990), among others, reported mixed results.

Causality test, first proposed by Granger (1969) and extended by Sims (1972), is based on F-statistic to test for the joint significance of particular lags of the

(4) Friedman (1956), however, argued that changes in the quantity of money will result in asset substitution leading to changes in both the velocity of money and income with the result that prices will not change proportionately. 
independent variables. For two economic variables (i.e. $\mathrm{X}_{\mathrm{t}}$ and $\mathrm{Y}_{\mathrm{t}}$ ), defined causality in terms of prediction ability. ${ }^{5}$ ) The time series $\mathrm{X}_{\mathrm{t}}$ is said to 'Granger cause' $\mathrm{Y}_{\mathrm{t}}$ if this leads to a better prediction of $Y_{t}$ by using $Y_{t}$ together with $X_{t}$ than by simply using $Y_{t}$. The test relies on temporal predictive power of one variable as an indication of its causal influence on the other. This can be done by first regressing current values of $\mathrm{Y}_{\mathrm{t}}$ on its past values and past values of $\mathrm{X}_{\mathrm{t}}$. The null hypothesis to be tested is that the coefficients on past values of $X_{t}$ are not significantly different from zero as a group. To determine whether causality runs in the other direction, the test is repeated by interchanging $\mathrm{X}$ and $\mathrm{Y}$ and test the joint significance of the coefficients of $\mathrm{Y}_{\mathrm{t}}$.

However, this bivariate causality test raises the possibility of an omitted variable bias. To overcome this problem, it is suggested to use a multivariate vector autoregressive (VAR) model. In the VAR approach, the economic system is represented as a stochastic process described by a vector of random variables. In this unrestricted system, there is no a priori endo-exogenous division of variables. It consists of regressing each current variable in the model on lagged values of itself and lagged values of all the other variables in the system. Algebraically, the unrestricted VAR can be described as:

$$
\left[\begin{array}{c}
M T_{t} \\
N O Y_{t} \\
P_{t}
\end{array}\right]=\left[\begin{array}{llll}
a_{11}(L) & a_{12}(L) & a_{12}(L) \\
a_{21}(L) & a_{22}(L) & a_{23}(L) \\
a_{31}(L) & a_{32}(L) & a_{33}(L)
\end{array}\right] \times\left[\begin{array}{c}
M t_{t} \\
N O Y_{t} \\
P t_{t}
\end{array}\right]+\left[\begin{array}{c}
u_{t 1} \\
u_{t 2} \\
u_{t 3}
\end{array}\right]
$$

Where $\mathrm{M}_{\mathrm{t}}$ is money supply (M1), NOY is real non-oil GDP, and $\mathrm{P}_{\mathrm{t}}$ is the price level (Consumer price index). $\mathrm{a}_{\mathrm{ij}}$ 's are the estimated coefficients and $\mathrm{L}$ denotes a lag operator. $\mathrm{u}_{\mathrm{i}}(\mathrm{i}=1,2,3)$ is a column vector of random errors assumed to be uncorrelated.

Since in this system all equations involve only lagged variables on their right-hand sides, and since these variables by definition are not correlated with the error term, use of ordinary least squares (OLS) to each equation separately will provide efficient and consistent estimates of the parameters ${ }^{(6)}$. Although there are no zero restrictions imposed, it is not possible, in practice, to avoid imposing some prior restrictions on a VAR system. Therefore, the choice of the appropriate lag length becomes important. Charemza and Deadman (1992) suggested relating the maximum lag length to the possible existence of autocorrelation in the disturbances ${ }^{()}$.

The estimated coefficients from a VAR are difficult to interpret. Therefore, it is common to do dynamic simulations by calculating impulse response (IR) and variance decomposition (VD) functions. The variance decomposition report the proportion of the forecast error of each endogenous variables that is accounted for by each of the other variables. The impulse response functions are the dynamic response of each

(5) There are other methods of testing causality, i.e. Sims (1972), and Pierce and Haugh (1977). Although Sim's test is widely used, Granger's method is preferred because it saves degrees of freedom. Moreover, Geweke et al. (1983) recommended the use of Granger's test because of its desirable statistical properties.

(6) However, Sims (1982, 1986), Sargent (1984), Cooley and LeRoy (1985) and Leamer (1985) criticized atheoretical VAR approach.

(7) The imposition of arbitrary lag length, such as equal lag length for all variables used, is considered too restrictive and can lead to biased results. For more details on this subject see Ahking and Miller (1985). 
endogenous variable to a one standard deviation random shock given to one of the other variables in the system. It should be noted that the results may be sensitive to the ordering of the variables. Therefore, different orderings should be used to test the robustness of the model.

Causality and vector autoregressive techniques require that the time series involved exhibit covariance stationarity to avoid getting spurious results. Nelson and Plosser (1982) and Nelson and Kang (1981, 1984) showed that ignoring the trend in the series would lead to serious econometric consequences. In order to investigate the stationarity properties of the data, a univariate analysis of the time series is carried out by testing for the presence of a unit root utilizing augmented Dickey-Fuller (ADF) tests (see Dickey and Fuller (1979)). This is done by forming and estimating the following regression:

$$
\Delta X_{t}=\beta_{0}+\beta_{1} X_{t-1}+\sum_{i=1}^{k} \alpha_{i} \Delta X_{t-i}+e_{t}
$$

Where $\Delta$ represents first differences. The null hypothesis is $\beta_{1}=0$ with significance level provided by Dickey and Fuller (1979) and Mackinnon (1991), among others. Lagged first differences of the dependent variable are included to account for autoregressive-moving average terms. Phillips (1987) and Phillips and Perron (1988) suggested a non-parametric procedure to correct for serial correlation in the errors of equation (2). Since the results of these tests often depend on the number of lags included, careful attention must be paid to the lag length selection. The lag length, $\mathrm{k}$, is set to achieve white-noise error structure in $e_{t}$. A time series is said to be stationary if its mean, variance and covariances are all invariant with respect to time. A time series requiring first-order differencing to achieve stationarity is said to be integrated of order one, I(1). Generally, any linear combination of two I(1) time series will also be an I(1) series. However, if there exists some linear combination of the two series which itself is $\mathrm{I}(0)$, then cointegration exists.

The concept of cointegration provides a useful statistical definition of long-run equilibrium relationship between two or more non-stationary time series. Researchers suggested a number of methods to test for cointegration. The most popular method is due to Johansen (1988) and Johansen and Juselius (1990, 1992), JJ thereafter. Engle and Granger (1987) suggested a two-step procedure to test for cointegration. In the first stage, a static (cointegrating) regression equation relating variables under investigation is estimated and, then, its residuals are tested for stationarity using unit root tests outlined above. Sargan and Bhargava (1983) suggested another test using Durbin-Watson statistic from the cointegrating equation. If this statistic is lower than the critical value, then cointegration will be rejected. However, Engle and Granger (1987) test is valid only in a bivariate case where a unique cointegrating vector is guaranteed. In case of more than two variables, Banerjee et al. (1993), and Cuthbertson et al. (1992) showed that JJ procedure is preferred. Also, Gonzalo (1994) compared the performance of the cointegration tests using a Monte Carlo study and found that JJ procedure is the most powerful even for the bivariate system. He showed that JJ approach has consistent estimates even if the errors are non-Gaussian and the 
dynamics are not known.

In the following sub-section, we provide a brief explanation of Johansen procedure which draws heavily from the Johansen and Juselius $(1990,1992)$. Let $X_{t}$ be a $p \times 1$ vector of $\mathrm{I}(1)$ variables expressed as a vector autoregression;

$$
X_{t}=\sum_{i=1}^{k} \pi_{i} X_{t-i}+\mu+e_{t}
$$

Subtracting $X_{t-1}$ from both sides of (3), adding and subtracting $(\pi-1) X_{t-1}$ from the right hand side and rearranging we get:

$$
\Delta X_{t}=\sum_{i=1}^{k-1} \Gamma_{i} \Delta X_{t-i}-\pi X_{t-k}+\mu+e_{t}
$$

where $\pi=\mathrm{I}-\pi_{1}-\pi_{2}-\ldots \ldots \ldots \ldots-\pi_{\mathrm{k}}$ and $\Gamma_{\mathrm{i}} \mathrm{s}$ are linear combinations of the $\pi_{\mathrm{i}} \mathrm{s}$. All longrun information is contained in the levels terms, $\pi \mathrm{X}_{\mathrm{t}-\mathrm{k}}$. A relation between $\Delta \mathrm{X}_{\mathrm{t}}$ and $\pi \mathrm{X}_{\mathrm{t}}$ $k$ can exist only if $\pi \mathrm{X}_{\mathrm{t}-\mathrm{k}}$ defines one or more stationary linear combinations. For example, in case of three variables, possible outcomes are; i) $\operatorname{rank}(\pi)=3$, which means that all elements of $X_{t}$ are stationary; ii) $\operatorname{rank}(\pi)=0$, which means the system must be estimated in a differenced form; iii) $0<\operatorname{rank}(\pi)=r<p(p=3$ in our study), then we can write $\pi=\alpha \beta$ where $\beta$ is a matrix of cointegrating vectors and $\alpha$ is a matrix of error correction coefficients. $\beta$ matrix has the property that $\beta^{\circ} X_{t}$ is stationary even though $\mathrm{X}_{\mathrm{t}}$ is not stationary.

Estimation begins with regressing $\Delta X_{t}$ and $X_{t-1}$ on lagged $\Delta X_{t-1}$ and constant term, yielding residuals $R_{o t}$ and $R_{1 t}$, respectively. Maximum likelihood estimates of $\beta$ are the eigenvectors corresponding to the $r$ largest eigenvalues in solution to:

$$
\left|\lambda S_{11} S_{10} S_{00}^{-1} S_{01}\right|=0
$$

where $S_{\mathrm{ij}}$ are the product moment matrices of the residuals:

$$
\mathrm{S}_{\mathrm{ij}}=(1 / \mathrm{T}) \sum_{t=1}^{T} R_{i t} R_{j t} \quad \mathrm{i}, \mathrm{j}=0,1
$$

Two tests for determining the number of cointegrating vectors, $r$, are based on the number of significant eigenvalues in (5). The first, denoted as the trace test, examines the hypothesis of at most $r$ cointegrating vectors against the general unrestricted model $\mathrm{r}=\mathrm{p}$. It can be found by calculating the following likelihood test statistic:

$$
\mathrm{LR}=-\mathrm{T} \sum_{i=r+1}^{3} \ln \left(1-\lambda_{i}\right), \quad \mathrm{r}=0,1
$$

The second, denoted as the maximum eigenvalue test, tests the null hypothesis that there are $\mathrm{r}$ cointegrating vectors against the alternative that there exists $\mathrm{r}+1$ cointegrating vectors and is calculated as follows:

$$
\mathrm{LR}=-\mathrm{T} \ln \left(1-\lambda_{\mathrm{r}+1}\right), \quad \mathrm{r}=0,1,2
$$


Johansen (1988) showed that both tests will have non-standard distribution under the null hypothesis. Asymptotic critical values have been tabulated in Johansen (1988), Johansen and Juselius (1990), and Osterwald-Lenum (1992).

\section{Data and Empirical Results}

The paper uses quarterly data from 1971.1 to $1995.4^{\left({ }^{8}\right)}$. All variables are in log form. The first stage in investigating empirical relationships between money on the one hand and non-oil GDP and Prices on the other, is to determine the order of integration of the individual time series. Table (1) reports the results of ADF and PP tests in both levels and first differences. Optimum lags for ADF test were obtained through minimization of Akiake Information Critirion (AIC), and for PP by utilizing Newey-West (1987) method which corrects for heteroskedasticity and autocorrelation in residuals. These results indicate that the first differences of the logs of M1, NOY, and $\mathrm{P}$ are stationary $\left.{ }^{(}\right)$. This means that the series of these variables are integrated of order one ( I(1)).

Table (1) Unit root tests

\begin{tabular}{|c|c|c|c|c|}
\hline \multirow[t]{2}{*}{ Variable } & \multicolumn{2}{|c|}{ ADF } & \multicolumn{2}{|c|}{$\mathrm{PP}$} \\
\hline & $\mathrm{N}^{\mathrm{a}}$ & $C \& T^{b}$ & $\mathrm{~N}^{\mathrm{a}}$ & $C \& T^{b}$ \\
\hline LM & $\begin{array}{c}0.59^{*} \\
(-1.67)\end{array}$ & $\begin{array}{l}-2.01^{*} \\
(-3.42)\end{array}$ & $\begin{array}{c}1.92 \\
(-9.16)\end{array}$ & $\begin{array}{c}-1.06 \\
(-11.13)\end{array}$ \\
\hline LNOY & $\begin{array}{l}0.54^{*} \\
(-2.08)\end{array}$ & $\begin{array}{l}-2.80 \\
(-3.71)\end{array}$ & $\begin{array}{c}1.33 \\
(-3.68) \\
\end{array}$ & $\begin{array}{c}-1.86 \\
(-4.72) \\
\end{array}$ \\
\hline LP & $\begin{array}{c}0.33^{*} \\
(-1.41)\end{array}$ & $\begin{array}{l}-2.53 \\
(-2.27)\end{array}$ & $\begin{array}{c}1.77 \\
(-5.61)\end{array}$ & $\begin{array}{c}-1.40 \\
(-7.05)\end{array}$ \\
\hline
\end{tabular}

- Numbers in parentheses are for the tests in first differences.

- a: $5 \%$ critical value is $-1.94,10 \%$ critical value is -1.61 .

- b: $5 \%$ critical value is -3.41 .

- Critical values are taken from Mackinnon (1991).

* indicates 4 lags, and ** indicates 3 lags based on AIC For ADF. For PP test the lag length is 4 according to Newey-West (1987) criteria.

According to Engle and Granger (1987), a model (i.e. VAR) in differences is misspecified if the time series are cointegrated. The misspecification is due to omission of long-run equilibrium relationships implied by cointegration. In order to account for this possibility, alternative cointegration tests have been applied. Johansen (1988) maximum likelihood (JJ), ADF, PP, and CIRDW tests have been applied. The lag length for variables in $\mathrm{JJ}$ test was determined by a sequence of likelihood ratio tests and

(8) Data are taken from Saudi Arabian Monetary Agency (SAMA) annual reports. All data are quarterly except for non-oil GDP which is annual. An interpolation method due to Goldstein and Khan (1976) was used to convert annual data to quarterly. Quarterly figures within any year can be interpolated as:

1 st quarter $=0.05469 \mathrm{Xt}-1+0.23437 \mathrm{Xt}-0.03906 \mathrm{Xt}+1$

2nd quarter $=0.00781 \mathrm{Xt}-1+0.26563 \mathrm{Xt}-0.02344 \mathrm{Xt}+1$

3rd quarter $=-0.02344 \mathrm{Xt}-1+0.26563 \mathrm{Xt}+0.00871 \mathrm{Xt}+1$

4 th quarter $=-0.03906 \mathrm{Xt}-1+0.23437 \mathrm{Xt}+0.05469 \mathrm{Xt}+1$

(9) The only exception is for LP when using ADF with constant and time trend. Other tests show that LP contains a unit root. Therefore, we disregard this result. 
found that four lags are optimal, for ADF by minimizing AIC, and for PP by utilizing Newey-West method. Johansen trace and $\lambda_{\max }$ test: statistics, reported in Table (2), show that we cannot reject the hypothesis of cointegrating vectors at the 1 percent level of significance. The test indicates the existence of two cointegrating vectors. Cointegrating Durbin-Watson (CIDW) test, and ADF and PP tests on residuals of cointegrating equation confirm Johansen test result. This means there exists a long-run relationship between LM1, LNOY, and LP. Hence, all the variables were entered in VAR model in logged levels. The optimal lag length on the VARs was derived using a sequence of likelihood ratio tests and through minimization of AIC. It was found that five lags are optimal ${ }^{(10)}$.

Table (2) Cointegration tests

\begin{tabular}{|c|c|c|c|c|c|}
\hline Eigenvalue & $\lambda_{\mathrm{MAX}}$ & $5 \%$ & Trace & $5 \%$ & Hypothesis \\
\hline 0.26 & 41.94 & 17.89 & 60.07 & 24.31 & $\mathrm{r} \leq 0^{* *}$ \\
\hline 0.18 & 17.33 & 11.44 & 18.13 & 12.53 & $\mathrm{r} \leq 1^{* *}$ \\
\hline 0.009 & 0.80 & 3.84 & 0.80 & 3.84 & $\mathrm{r} \leq 2$ \\
\hline \multicolumn{2}{|r|}{ CIDW=0.65 } & \multicolumn{2}{|c|}{$\mathrm{ADF}=-3.21^{*}$} & \multicolumn{2}{c|}{$\mathrm{PP}=-4.19^{*}$} \\
\hline
\end{tabular}

\# Johansen test with no constant or time trend.

** significant at $1 \%$ level of significance.

* significant at 5\% level of significance, ( critical value -1.94).

- Critical values for ADF and PP are taken from Mackinnon (1991).

*** significant at $5 \%$ level of significance, (critical value 0.38 , taken from Sargan and Bhargava (1983)).

- Critical values for Johansen test are taken from Osterwlad-Lenum (1992).

Since the equations of the VAR contain only lagged values of the variables, correlation of residuals across equations will reflect any contemporaneous relations among the variables. To deal with contemporaneous correlation in the computation of variance decomposition (VD) and impulse response functions (IR), the errors are orthogonalized by a Cholseky decomposition so that the covariance matrix of the resulting innovations is diagonal ${ }^{\left.(1)^{\prime}\right)}$.

(10) A likelihood test statistic was calculated to test the weak exogeniety of each of the variables, LM1, LP, LNOY. The test statistic that all these variables are all weakly exogenous is 4.87 , which should be compared with $\chi 2(2) 90 \%=4.61$. This indicates that there may be some information in the equation for $\mathrm{p}$ and noy, and as a consequence it may not be efficient to analyze a single equation to estimate the parameters in individual equations. Also, a VAR model based on the two cointegrating vectors was estimated and analyzed. The results obtained are almost the same. Therefore, they are not reported here to conserve space.

(11) There are several plausible alternative structures to identifying the system (i.e. Bernarke (1986), Blanchard and Quah (1989), and Robertson and Orden (1990) among others), the one presented here has been used extensively in the applied research and found to perform well. Each method has its own shortcomings. 
Table (3) shows the variance decomposition for the variables for first, tenth, and twenith periods. Runkle (1987) noted that reporting VDs without their standard errors is similar to reporting regression coefficients without $t$ statistics. Thus, we use a Monte Carlo simulations with 1000 draws to generate these standard errors. The point estimate is judged to be statistically significant if it is at least twice the standard error. From Table (3), it can be noted that a significant feedback exists between M1 and NOY. However, the causal relationship is stronger from the monetary policy variable to the income variable than vice versa. Innovations in M1 explain 43 percent of variations in NOY at the end of the 20-quarter period, while NOY innovations explain about 30 percent of the variation in M1. In the case of price level and M1, and P and NOY, the causality relationships exist in one direction, from each of M1 and NOY to P without feedback. In fact, M1 and NOY explain higher proportion of the price level than the innovation in the price level itself (i.e. $51 \%$ vs. $48 \%$ for M1 and $34 \%$ vs. $8 \%$ at the end of $10^{\text {th }}$ quarter period for NOY). To check the robustness of the results, different ordering of the variables were tried. The results are relatively similar for either order of decomposition and, hence, they are not reported here.

Table (3) Variance Decompositions

\begin{tabular}{|c|c|c|c|c|c|c|c|c|c|}
\hline \multirow{2}{*}{ EFFECT ON } & \multicolumn{9}{|c|}{ LMURCE OF SHOCK } \\
\hline & 1 & 10 & 20 & 1 & 10 & 20 & 1 & 10 & 20 \\
\hline LM & $100^{*}$ & $60.0^{*}$ & $22^{\prime \prime}$ & 2 & $38.0^{*}$ & $30.0^{*}$ & 0.00 & 2.00 & 10.00 \\
& & & & & & & & & \\
\hline LNOY & $4.00^{*}$ & $31.00^{*}$ & $43.00^{*}$ & $94.00^{*}$ & $67.00^{*}$ & $45.00^{*}$ & 2.00 & 2.00 & 12.00 \\
\hline LP & $51.0^{*}$ & $58.00^{*}$ & $59.00^{*}$ & 1.00 & $34.00^{*}$ & $26.00^{*}$ & $48.00^{*}$ & 8.00 & 15.00 \\
\hline
\end{tabular}

- standard errors are $1.7,6.7$, and 8.6 for periods 1,10 , and 20 respectively, ${ }^{(*)}$ that the value is at least twice the standard error.

In order to investigate these relationships further, we estimate impulse response functions. Figures 1a, 1b, 2a, 2b, 3a, and $3 \mathrm{~b}$ plot these impulse response functions for each one of the three variables (M1, NOY, and P) with respect to innovations equivalent to 1 percent point rise in the other two variables. These figures also include standard errors bands ( \pm two standard deviations). The solid lines in the graphs are the mean responses, while the dashed lines are approximate $95 \%$ confidence intervals. Figures 1a,b plot the impulse responses of M1 to a shock from $\mathrm{P}$ and NOY respectively. They show how the dependent variables respond over a 20-quarter horizon to a one standard-deviation change in each shock. The confidence interval for the response of money to price level ( figure 1a) are not too wide, indicating that the impulse responses are reasonably precise. It shows no response at time zero, but responses from period one onward. Eventually, it converges to zero. This indicates insignificant responses of money to a shock in price level.

(*) The author would like to thank one of the refrees for his helpful comments. Any remaining errors are the sole responsibility of the author. 


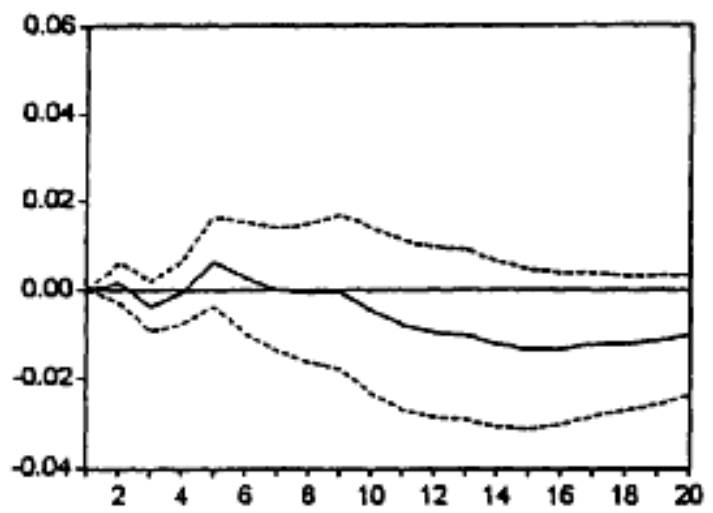

Figure (1a) Response of M1 to one S.D. Innovations \pm 2 S.E. in P.

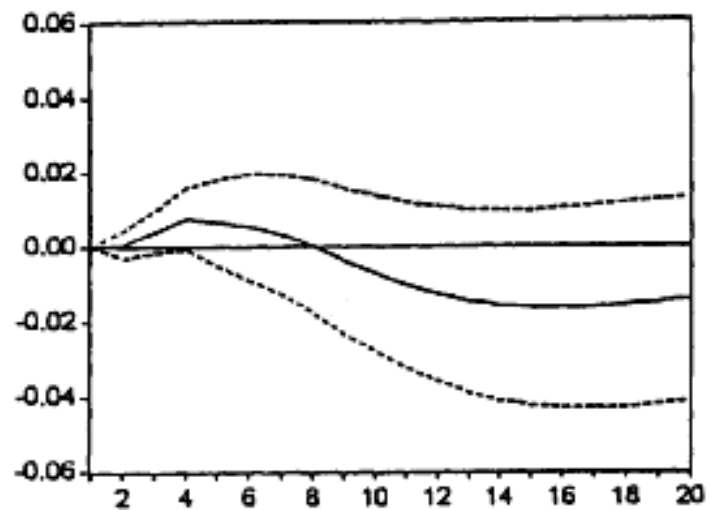

Figure (2a) Response of NOY to one S.D. Innovations \pm 2 S.E. in P.

Figures $1 \mathrm{~b}$ and $2 \mathrm{~b}$ show bi-directional causality between M1 and NOY. For figure $1 \mathrm{~b}$, the lower $95 \%$ confidence band is above zero all the time, while the lower $95 \%$ confidence band for figure $2 \mathrm{~b}$ becomes below zero at the 10 -quarter period. This indicates that causality running from M1 to NOY is relatively stronger than the other way which confirms the result reached using variance decompositions. The positive shocks to one of these two variables lead to an increase in the other variable. This result suggest that monetary policy has a significant influence on the real sector of the economy. 


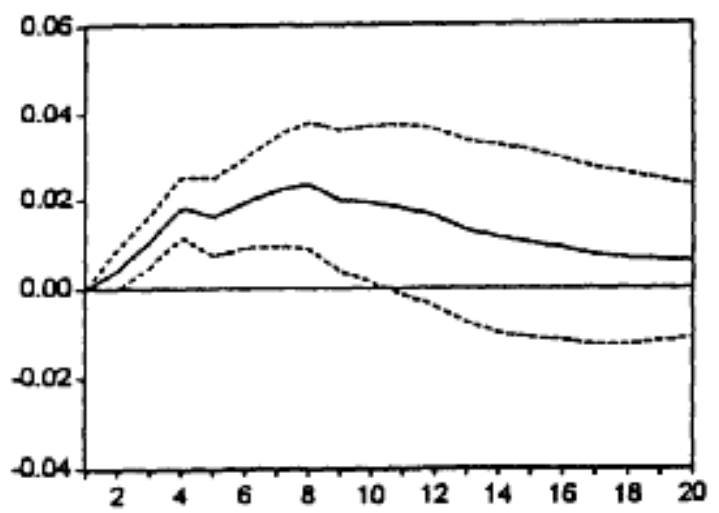

Figure (1b) Response of M1 to one S.D. Innovations \pm 2 S.E. in NOY.

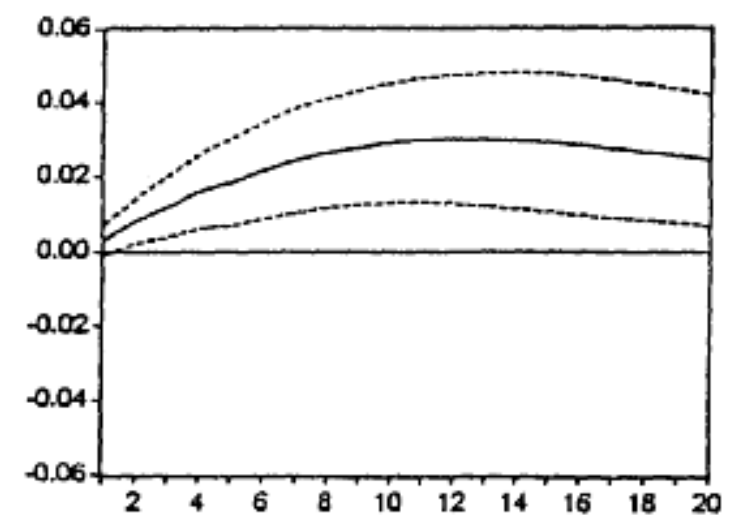

Figure (2b) Response of NOY to one S.D. Innovations \pm 2 S.E. in M1.

Figures 3a, b show that the money supply (M1) and non-oil GDP have the impact on price level. A shock to M1 initially has a negative effect on P. In period three, it starts to increase and becomes positive. The peak effect occurs in the eighth quarter and gradually diminishes and becomes insignificant at the 18-quarter period. A shock to NOY produces insignificant response in P. However, the impact of NOY becomes significant in period three and reaches its peak in period 4. This effect becomes insignificant in period eight. Although, one can see that the impact of M1 on P is relatively stronger than the impact of NOY on $\mathrm{P}$, this supports the view that inflationary pressure in Saudi Arabia is not entirely caused by monetary factors. 


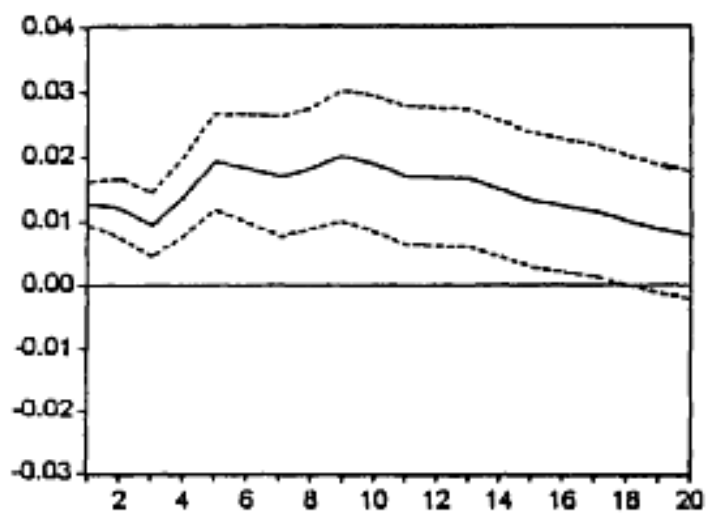

Figure (3a) Response of P to one S.D. Innovations \pm 2 S.E. in M1.

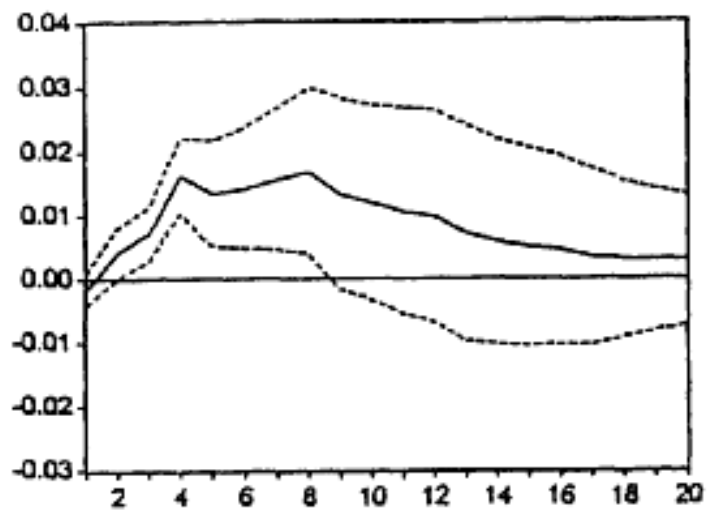

Figure (3b) Response of $P$ to one S.D. Innovations \pm 2 S.E. in NOY.

\section{Conclusion}

This paper examines the empirical relationships connecting money to income and prices within the context of a vector autoregressive model using quarterly Saudi data. The paper, also, investigates the statistical properties of time series of the variables. It was found that all series are difference stationary and cointegrated. The impact of one variable on the other variables is evaluated through computation of variance decompositions and impulse response functions for which standard errors are calculated through Monte Carlo simulations. The results indicate a bi-directional causality between money and income and unidirectional causality between money and prices and between income and prices. The causality runs from money and income to prices without feedback. 
These findings have useful theoretical and policy implications for the policymakers. First, the bi-directional causality between money supply and nominal output is consistent with the Keynesian and monetarist theories. Second, money supply (narrowly defined) appears to be contributing to inflationary pressure. This contradicts the widely held view that inflation in Saudi Arabia is mainly caused by demand pressures. It, also, casts some doubt on the presumption that, in an oil dependent economy, monetary policy is endogenous and hence ineffective. In contrast, the monetarist view that inflation is a monetary phenomenon is partially accepted. Third, the strong effect of money supply on income may result from both increase in demand and supply. Fourth, if monetary authorities are determined to maintain price stability, controlling money supply may lead to stable prices at the consumer's level, but may slow down real activity. Therefore, monetary policy should be supplemented by fiscal measures to reduce infrastructure bottlenecks and supply constraints.

\section{References}

Ahking, F. W., and Miller, S. M. (1985), "The Relationship between Government Deficits, Money Growth, and Inflation," Journal of Macroeconomics, vol. 7, 447-467.

Banerjee, A., Dolado, J., Galbraith, J., and Hendry, D. (1993), "Cointegration, ErrorCorrection, and Econometric Analysis of Non-Stationary Data," Oxford, Oxford University Press.

Benderly, J., and Zwick, B. (1985), "Money, Unemployment and Inflation," Review of Economics and Statistics, vol. 67, 139-143.

Bernarke, A., (1986), "Alternative Explanations for the Money-Income Correlation," CarengieRochester Conference Series on Public Policy, vol. 25, 49-100.

Blanchard, O.J., and Quah, D. "The Dynamic Effects of Aggergate Demand and Supply Disturbances." American Economic Review, vol. 79, 655-673.

Charemza, W. W., and Deadman, D. F. (1992), "New Directions in Econometric Practice" Vermont, Edward Elgar.

Cooley, T. F., and LeRoy, S. F. (1985), “A Theoretical Macroeconomics,” Journal of Monetary Economics, vol. 16, 283-308.

Cuthberton, K., Hall, S., and Taylor, M. (1992), "Applied Econometric Techniques”, Ann Arbor, The University of Michigan Press,

Dickey, D. A., and Fuller, W. A. (1979), "Distribution of the Estimators for Autoregressive Time Series with a Unit Root", Journal of the American Statistical Association, vol. 74, 427-431.

Engle, R., and Granger, C. W. J. (1987), "Co-Integration and Error Correction: Representation, Estimation, and Testing”, Econometrica, vol. 55, 251-276.

Fackler, J. S. (1985), "An Empirical Analysis of the Markets for Goods, Money, and Credit," Journal of Money, Credit and Banking, vol. 17, 28-42.

Fadil, F. G. (1989), "Money, Income, and Sterilization: Tests for Causality in the Oil Economy of Kuwait", Applied Economics, vol. 21, 1305-1324.

Friedman, M. (1956), "The Quantity Theory of Money: A Restatement," in Milton Friedman (ed.), Studies in the Quantity Theory of Money, University of Chicago Press, Chicago, , (1970), "The Counter-Revolution in Monetary Theory", IEA, Occasional Paper, 33.

Friedman, M., and Schwartz, A. (1963), "A Monetary History of the United States 18671960," Princeton, Princeton University Press.

(1982), "Monetary Trends in the United States and the United Kingdom, their Relation to Income, Prices, and Interest Rates, 1876-1970," Chicago, University of Chicago Press. 
Geweke, J. R., Meese, R., and Dent, W. T. (1983), "Comparing Alternative Tests of Causality in Temporal Systems: Analytical Results and Experimental Evidence," Journal of Econometrics, vol. 21, 161-194.

Goldstien, M., and Khan, M. (1976), "Large Versus Small Price Changes and the Demand for Imports", IMF Staff Papers, vol. 23, 200-225.

Gonzalo, C. (1994), "Five Alternative Methods of Estimating Long-Run Equilibrium Relationship," Journal of Econometrics, vol. 60, 203-233.

Granger, C. W. J. (1969), "Investigating Causal Relations by Econometric Models and CrossSpectral Methods," Econometrics, vol. 37, 424-438.

Johansen, S. (1988), "Statistical Analysis of Cointegration Vectors", Journal of Economic Dynamics and Control, vol. 12, 231-254.

Johansen S., and Juselius, K. (1990), "Maximum Likelihood Estimation and Inference on Cointegration with Applications to the Demand for Money", Oxford Bulletin of Economics and Statistics, vol. 52, 169-210.

(1992), "Testing Structural Hypotheses in a Multivariate Cointegration Analysis of the PPP and UIP for UK", Journal of Econometrics, vol. 53, 211-244.

Jones, J. D., and Uri, N. D. (1987), "Money, Inflation, and Causality: Another Look at the Evidence for the USA, 1953-1984," Applied Economics, vol. 19, 619-634.

Jones, J., and Sattar, Z. (1988), "Money, Inflation, Output, and Causality: The Bang Case, 1974-1985," The Bangladesh Development Studies, vol. 16, 73-83.

Leamer, E. E. (1985), "Vector Autoregressions for Causal Inference", Carnegie-Rochester Conference Series on Public Policy, vol. 22, 255-304.

Lee, S. Y., and Li, W. K. (1983), "Money, Income, and Prices and their Lead-Lag Relationships in Singapore," Singapore Economic Review, vol. 28, 73-87.

Mackinnon, J. (1991), "Critical Values for Cointegration Tests", in R. F. Engle and C. W. J. Granger (eds.), Long-run Economic Relationships: Readings in Cointegration, Oxford, Oxford Univeristy Press,

Nelson, C. R., and Kang, H. (1981), "Pitfalls in the Use of Time as an Explanatory Variable in Regression," Journal of Business and Economic Statistics, vol. 2, (1984), 73-82. "Supurious Periodicity in Inappropriately Determined Time Series," Econometrics, vol. 49, 741-751.

Nelson, C. R., and Plosser, C. I. (1982), "Trends and Random Walks in Macroeconomic Time Series: Some Evidence and Implications," Journal of Monetary Economics, vol. 10, 139 162.

Nelson, C.R., and Schwert, G. W. (1982), "Tests for Predictive Relationships between TimeSeries Variables: a Monte Carlo Investigation," Journal of the American Statistical Association, vol. 77, 11-18.

Newey, W., and West, K. (1987), “A Simple Positive Semi-Definite Heteroskedasticity and Autocorrelation Consistent Covariance Matrix" Econometrica, vol. 55, 703-708.

Osterwald-Lenum, M. (1992), "A Note with Fractiles of the Asymptotic Distribution of the Maximum Likelihood Cointegration Rank Test Statistics: Four Cases", Oxford Bulletin of Economics and Statistics, vol. 45, 461-472.

Parikh, A. (1990), "Money Supply and Prices in Indonesia 1969-1980: An Econometric Investigation," Applied Economics, vol. 22, 1479-1494.

Pearce, D. A.. and Haugh, L. D. (1977), "Causality in Temporal System: Characterizations and Survey," Journal of Econometrics, vol. 5, 265-293.

Phillips, P. C. B. (1987), "Time Series Regression with a Unit Root”, Econometrica, vol. 55, 277-301.

Phillips, P. C. B, and Perron, P. (1988), “Testing for a Unit Root in Time Series Regression", Biometrika, vol. 75, 335-346. 
Quddus, M., Liu, J.T., and Butler, J. S. (1989), "Money, Prices, and Causality: The Chinese Hyperinflation, 1946-1949, Reexamined," Journal of Macroeconomics, vol. 11, 447453.

Robertson, J., and Orden, D. (1990), "Monetary Impacts on Prices in the Short and Long Run: Some Evidence from New Zealand." American Journal of Agricultural Economics, vol. 72, pp. 160-171.

Rosser, J. B., and Sheehan, R. G. (1995), "A Vector Autoregressive Model of the Saudi Arabian Economy," Journal of Economics and Business, vol. 47, 79-90.

Runkle, D. E. (1987), "Vector Autoregressions and Reality," Journal of Business and Economic Statistics, vol. 5, 437-442.

Sargan, J. D. and Bhargava, A. (1983), "Testing Residuals from Least Squares Regression for Being Generated by the Gaussian Random Walk", Econometrica, vol. 51, 153-174.

Sargent, T. J. (1984 ), "Autoregressions, Expectations, and Advice," American Economic Review, vol. 74, 408-415.

Saudi Arabian Monetary Agency (SAMA), Annual Report, Riyadh, Various Issues.

Sims, C. A. (1972), "Money, Income, and Causality", American Economic Review, vol. 62, 540552.

, (1982), "Policy Analysis with Econometric Models", Brookings Papers on Economics Activity, vol. 1, 107-152.

, (1986), “Are Forecasting Models Usable for Policy Analysis?" Quarterly Review of the Federal Reserve Bank of Minneapolis, vol. 10, 2-15.

Togan, S. (1987), "The Influence of Money and the Rate of Interest on the Rate of Inflation in a Financially Repressed Economy: The Case of Turkey," Applied Economics, vol. 19, 1585-1601.

Turnovsky, S., and Wohar, M. (1984), "Monetarism and the Aggergate Economy: Some Long Run Evidence," Review of Economics and Statistics, vol. 66, 619-629. 
تحليل دينامي لدور النقود في المملكة العربية السعودية

$$
\begin{aligned}
& \text { حد بن سليمان البازعي } \\
& \text { أستاذ مشارك } \\
& \text { قسم الاقتصاد - كلية العلوم الإدارية المادية } \\
& \text { جامعة الملك سعود - الرياض - المملكة العربية السعودية الإدية }
\end{aligned}
$$

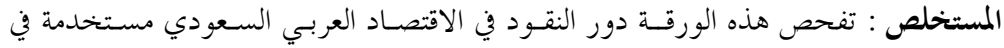

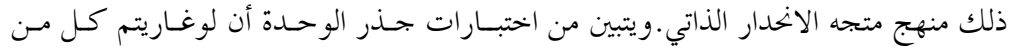

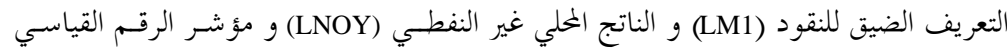

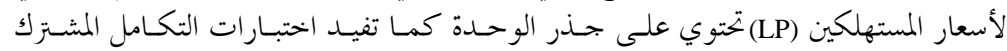

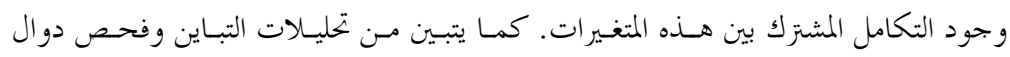

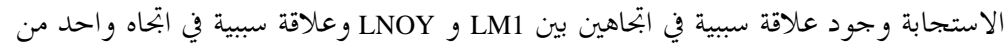

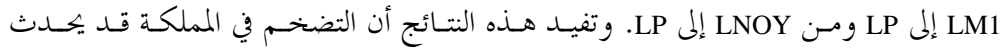

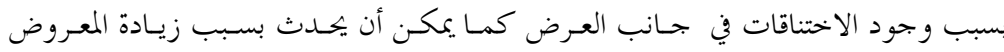

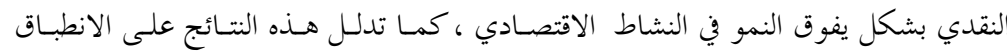

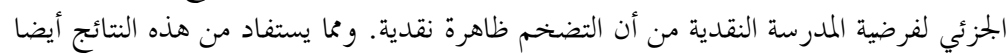

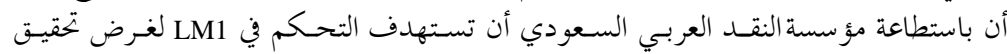

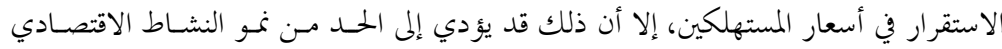

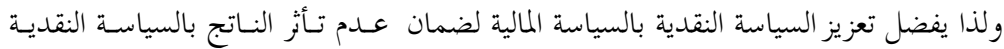

